\title{
As implicações da Reforma do Novo Ensino Médio na prática e na formação docente em Filosofia
}

The implications of the reform of the New High School in the practice and in the docent formation in Philosophy

\author{
Neuza Ferreira Rodrigues ${ }^{1}$ \\ Sônia Maria Lira Ferreira ${ }^{2}$
}

\section{Resumo}

A chegada do Novo Ensino Médio representa um golpe para o ensino de Filosofia: a disciplina deixa de ser obrigatória, voltando ao campo da instabilidade das políticas educacionais. O presente artigo tem como objetivo principal compreender os fenômenos de aceitação e de recusa do estudo de Filosofia pelos estudantes, investigando um problema já vivido, ou seja, o desinteresse acadêmico, que se torna emergente diante desse cenário educacional. Os professores de Filosofia são convocados a repensar o seu ensino e a sua formação docente, buscando superar a visão negativa da disciplina no Ensino Médio. A metodologia de pesquisa foi a pesquisa-ação, e o método aplicado, o fenomenológico.

Palavras-chave: Ensino de Filosofia. Novo Ensino Médio. Formação Docente.

\begin{abstract}
The emergence of the New High School has stricken Philosophy teaching; this school subject is no longer compulsory and has returned to the unstable field of education policies. The main purpose of the present paper is to understand the phenomena of acceptance and rejection of the study of Philosophy by the students, by addressing an already experienced problem, i.e. academic disinterest, which has emerged in the face of this education scenario. Philosophy teachers have been called to rethink their teaching action and their education, in an attempt to overcome the negative view of the subject in High School. The research methodology was the action-research, and the phenomenological method was applied.
\end{abstract}

Keywords: Philosophy Teaching. New High School. Teacher Education.

\footnotetext{
${ }^{1}$ Mestranda em Filosofia -UFCG; Especialista em História e Ensino de Filosofia; Professora do Estado do Paraíba.

${ }^{2}$ Mestrado em Filosofia pela Universidade Federal da Paraíba (2008). Doutoranda em Educação (UFAL). Professora da Universidade Federal de Campina Grande.
} 


\section{Introdução}

"A crise da educação do Brasil não é uma crise; é um projeto."

(Darcy Ribeiro)

O presente artigo se inicia com uma afirmativa de Darcy Ribeiro proferida em uma palestra em 1975, que ainda reverbera nos dias atuais. Essa assertiva justifica-se porque a educação brasileira tem vivenciado um período assombroso nos últimos anos. Não estamos em 1968, certamente, mas a censura e a perseguição são tão concretas e visíveis como outrora. A imagem do professor não é de educador, como aquele que contribui para a formação de todas as profissões, mas de "doutrinador". Além dessa visão negativa dos educadores, se tem a imagem das universidades públicas como aquelas que não espelham o futuro da ciência do país, pois são consideradas pelo governo vigente como "centros de balbúrdia". Outra imagem emblemática é a da educação pública no recorte do Ensino Médio, vista como "aquela que forma militantes políticos contaminados por ideologias", assim, a educação brasileira vive tempos dificieis e complexos em plena pandemia.

É com perplexidade que vemos essas imagens dos professores e das instituições educacionais serem deturpadas - em poucas palavras, o cenário é de intimidação aos professores, desvalorização do trabalho das instituições, cortes na educação básica e superior, implementação de reformas de ensino travestidas de melhorias, tudo isso, com a clara intenção de enfraquecer a formação humana e profissional ofertada aos estudantes das escolas públicas. Diante desse cenário, é pertinente apresentar uma síntese que versa sobre a intencionalidade da Reforma do Ensino Médio e, partir desta, o que nos interessa discutir são os ataques aos direitos dos estudantes e da classe docente:

Essa reforma não é simplesmente o modo mais eficaz de se organizar um Ensino Médio em crise, como se ela fosse 
neutra, racional ou simplesmente necessária. Ela é também um projeto de educação e de sociedade que formaliza e materializa interesses próprios: os interesses do capital no momento de sua crise. Desse modo, não é casual que a reforma do Ensino Médio tenha sido imposta por medida provisória menos de um mês após a consolidação do golpe institucional (MP 746/2016), sendo depois aprovada no Congresso Nacional (Lei $\mathrm{n}^{\circ}$ 13.415/2017), na esteira de tantas outras reformas, como a Emenda Constitucional 95, que congelou os gastos públicos diretos, a reforma trabalhista, a ampliação da terceirização e a reforma da Previdência (PIOLI ; SALA, 2020, p. 72).

Diante do exposto, o que se pode dizer é que não há neutralidade educacional, política e econômica nessas intervenções. Existe um projeto de Brasil e de sociedade que se constrói pela via da educação, da formação focada nos interesses da acumulação capitalista. Nesse novo projeto de Brasil, a educação nunca foi tão aviltada e, ao mesmo tempo, convocada a prestar seu serviço à sociedade, travando uma luta contra a desinformação, contra o negacionismo mortífero frente à situação calamitosa da pandemia de COVID-19, uma crise sanitária mundial que fez evidenciar as fragilidades de nosso país no âmbito econômico, social e, também educacional, aumentando as desigualdades entre educação pública e privada. Essa contextualização do cenário político-pedagógico é pertinente para começarmos a falar sobre o ensino de Filosofia afinal, ele não sai ileso desse contexto em que se encontra a educação brasileira.

Conforme já foi pontuado, em meio a essas lutas gerais da educação, há outra, relativa ao ensino de Filosofia, que é o foco de investigação deste trabalho acadêmico, e ela diz respeito à sobrevivência e permanência dessa disciplina no Ensino Médio para continuar contribuindo com a formação dos jovens. Essa é uma luta que se potencializa quando a disciplina sofre modificações nos documentos oficiais, com a Reforma do Novo Ensino 
Médio, Lei 13.415/2017 de 1 de março de 2017, deixando de ser um componente curricular obrigatório para as séries do Ensino Médio. Portanto, para compreender a situação que enfrenta os/as professores/as que estão à frente do ensino de Filosofia, cabe apresentar a história da implantação e da retirada dessa disciplina nos últimos anos, enquanto componente curricular em nosso país.

Em razão do cenário de instabilidade para a Filosofia, o problema motivador do presente artigo se constituiu na seguinte pergunta: Como se mostra o fenômeno do desinteresse dola estudante pela disciplina de Filosofia diante da Reforma do Novo Ensino Médio e, se a partir desta é pertinente pensar numa nova configuração da prática do ensino de Filosofia e da formação docente?

A partir dessa questão problematizadora, as pesquisadoras deram início à investigação do tema-problema mediante os passos da pesquisaação , pois na iminência da chegada do Novo Ensino Médio, se iniciou uma intervenção na busca de possibilitar modificações no ato de ensinar e aprender, os quais influenciam tanto no interesse quanto no desinteresse dos discentes em relação aos conteúdos filosóficos. A pesquisa se iniciou presencialmente antes da pandemia, no ano de 2019, na Escola Estadual de Ensino Fundamental e Médio Francisco Ernesto do Rêgo, localizada no Município de Queimadas (PB), com a elaboração e a vivência do seminário central. Deu-se continuidade à pesquisa nos anos de 2020 e 2021, com foco no aprofundamento da fundamentação teórica. A pesquisa foi realizada em sete turmas; destas, seis são do $2^{\circ}$ ano, e uma é de $1^{\circ}$ ano. O método de procedimentos aplicado foi o fenomenológico ao buscar atingir a essência do fenômeno investigado e, assim, envolver os sujeitos da pesquisa: pesquisadoras e sujeitos pesquisados na mudança de visão e interesse pelos conteúdos da disciplina de Filosofia vivenciados em sala de aula.

O objetivo principal visa compreender a aceitação e a recusa dos estudantes no que se refere ao estudo de Filosofia, problema que se torna emergente de compreensão tendo em vista a chegada da Reforma do Novo 
Ensino Médio e, para atingir esse objetivo, foram delineados os seguintes objetivos específicos:

- situar o ensino de Filosofia no contexto histórico das reformas do ensino médio;

- $\quad$ discutir a formação docente ofertada pela universidade com a intenção de compreender o fosso entre a mesma e a escola pública;

- redefinir o ensino de filosofia que se apresenta em sala de aula;

- interpretar o fenômeno do desinteresse dos/das discentes pelos conteúdos filosóficos mediante a interpretação das suas falas;

- resolver o problema constatado mediante uma ação de intervenção constituída e efetivada pelos sujeitos da pesquisa.

Nos guiando pela problemática apresentada, assim como pelos referidos objetivos daremos prosseguimento na investigação proposta do artigo tratando, incialmente, da Reforma do Ensino Médio e do seu impacto no ensino e na formação docente.

\section{A Reforma do Novo Ensino Médio}

Para tratarmos da Reforma do Novo Ensino Médio é imprescindível perfazer o caminho histórico da Filosofia como disciplina escolar no contexto histórico da educação brasileira. O que se dará destaque, diz respeito a retirada da Filosofia do currículo no período da ditadura militar, sob a acusação de ideologização, por supostamente ameaçar a ordem pretendida pelo Estado, isso ocorreu de acordo com Costa; Subtil (2016, p. 32): “[...] por não servir aos interesses políticos, econômicos e ideológicos do período". Assim, foram suprimidas do currículo escolar as disciplinas que propunham o desenvolvimento da criticidade do discente e, dentre elas, se encontrava a disciplina de Filosofia. É pertinente salientar que:

O Golpe Militar no Brasil protagonizou uma série de mudanças e reformas. Em se tratando do ensino de filosofia, a partir do ano de 1964, permanece como disciplina optativa, seguindo alterações da Lei n. 4.024 (1961), continuando assim até o ano de 1971, quando 
foi excluída do currículo e proibida de ser ensinada nas escolas (COSTA; SUBTIL, 2016, p. 30).

Quase 40 anos depois, em que a Filosofia foi afastada da escola e tratada como uma inimiga, a qual se pretendia deixar o mais longe possível das instituições educacionais, é demarcada a volta da mesma e da Sociologia ao Ensino Médio, em 1996 com a Lei de Diretrizes e Bases (LDB), projeto do então Senador Darcy Ribeiro. Ambas, foram citadas no texto da referida lei e apresentadas como conhecimentos necessários ao exercício da cidadania. No entanto, esse retorno ainda não tinha garantia de que elas se fizessem presentes no currículo como disciplinas no Ensino Médio. A Filosofia apenas consegue retornar de forma permanente às instituições de ensino em 2008, e, em menos de uma década, inicia outro percurso, com a chegada do novo Ensino Médio em 2017, de acordo com a Lei 13.415 de 2017, em que é ela perde o caráter de obrigatoriedade enquanto componente curricular, pois esta se presentifica tão somente como estudos e práticas, e não mais como uma disciplina obrigatória.

Essa mudança demonstra uma significativa perda de espaço anteriormente adquirido, na medida em que, não ficou claro o papel e a relevância que a Filosofia assume nos documentos oficiais. O ensino de Filosofia se encontra diluído nas competências e habilidades do itinerário formativo correspondente à área de Ciências Humanas e Sociais Aplicadas. Com esse cenário problemático e complexo que se mostrou em relação a esse ensino, se tornou urgente para os professores/as de Filosofia investigarem o problema da própria sobrevivência da Filosofia no Novo Ensino Médio.

Somando-se a essa supressão, a sobrevivência da Filosofia é posta em xeque também por outra razão. No contexto da Base Nacional Comum Curricular (BNCC), traz à tona uma proposta falseada de liberdade de escolha do discente de acordo com as áreas de conhecimento que mais the interessam para a sua formação. Vemos que aí se desenha um cenário preocupante de deformação da formação humana ne medida em que se volta a acentuar a prioridade da profissionalização ou, diga-se, do tecnicismo em 
detrimento da formação humana. Teremos uma formação na qual as disciplinas que buscam fomentar a criticidade do estudante para a realidade e o mundo que o circundam, ficam relegadas a um plano secundário, pois como afirmam Pioli; Sala (2020, p. 84) a “[...] reforma do Ensino Médio acaba por oferecer, para a maioria da juventude trabalhadora, apenas uma formação rápida, superficial e, acima de tudo, precária”, isso porque se modifica a composição obrigatória das áreas de ensino e se coloca o enfoque na formação profissional, caminhos esses que, na prática, se restringem às escolas públicas, sem abranger as escolas privadas. Aos estudantes deste último tipo de estabelecimento de ensino, vigorará a oferta de todos os eixos formativos, sem supressão, visando uma formação integral. Assim, acentua-se o fosso entre a educação pública e privada.

A reforma do Ensino Médio, mais do que dar ao discente a chance de escolher a área em que deseja estudar, "flexibilizando ou democratizando" sua escolha, implica em um possível enxugamento de matérias e de professores, pois ela envolve a não responsabilização do governo por essas futuras gerações ao ser delegada aos próprios estudantes a responsabilidade pelo aprimoramento de sua formação acadêmica e profissionalizante. Como afirma Lindberg (2019) na Coluna da Associação Nacional em FilosofiaANPOF:

A sensação de liberdade de escolha, tão difundida pelos órgãos governamentais, esconde o mecanismo mais perverso da reforma educacional. Como $40 \%$ da carga horária será destinada aos itinerários formativos, as demais áreas do conhecimento passarão ilesas ao crivo dos estudantes. Ao optar por um itinerário formativo em detrimento do outro, o estudante assume toda responsabilidade pela escolha feita.

É pertinente destacar outra questão alarmante, que emerge frente à reformulação da carga horária do Ensino Médio, que passará a ter itinerários gerais que computarão 1.800 horas na formação, abrindo-se espaço para o ensino EaD. O Ensino Médio poderá ter de $20 \%$ a $30 \%$ de sua carga horária 
nesse modelo de ensino, e, assustadoramente, na EJA (Educação de Jovens e Adultos), esse percentual sobe de $50 \%$ a $75 \%$ de ensino não presencial. Os professores da rede pública sabem das dificuldades que se apresentam aos alunos/as da EJA, uma realidade que se acentuou muito em tempos de pandemia, pois o ensino remoto proposto no ano de 2020, mostrou lacunas de aprendizagem e evidenciou a dificuldade de acesso dos/as estudantes das escolas públicas aos meios tecnológicos necessários para se realizar o ensino à distância.

É inegável o vertiginoso abismo de desigualdades que se desvelaram nesse ano de pandemia quando se fala nas diferentes condições dos estudantes da rede pública e daqueles da rede privada de ensino. Apesar das estratégias do Estado - e aqui nos referimos às medidas tomadas pelo governo no Estado da Paraíba - que passou a ofertar aulas remotas em plataformas digitais, materiais disponibilizados online ou na forma impressa e, até mesmo, se utilizou da formatação de aulas em canal de TV aberta, entretanto, o que se mostrou concretamente e o que se pode afirmar é o real fracasso dessa modalidade de ensino, a EaD. Esse resultado não está dissociado do retrato social e econômico do Brasil, como sendo o de um país em pobreza crescente. Muitas famílias tiveram que escolher entre pagar as suas necessidades básicas, ou outros gastos versus ter condições de acesso aos pacotes de dados de internet, o que resulta tacitamente em não ter condições de sustentar um dos vínculos possíveis de ensino para os seus filhos em 2020-2021. Muitos não têm uma casa que ofereça uma estrutura mínima para os estudos, que passou a ser inteiramente domiciliar; muitos dependem da escola para o recebimento de cestas básicas para suprir as refeições das crianças e adolescentes, anteriormente, garantidas pelas instituições. Essas situações se apresentam como pontos de reflexões para se discutir a relevância do ensino presencial das escolas públicas.

Quanto à compreensão da falha do ensino remoto, leva-se em conta que, fomos surpreendidos por uma mudança brusca que requisitou com urgência a nossa capacidade de reinvenção na forma de ensinar e, com ela, a de incentivar e motivar os/as discentes para a aprendizagem frente às 
limitações desse modelo de ensino, em que as relações intersubjetivas são mediatizadas por meios tecnológicos, empobrecendo as relações humanas. O que se pode dizer, é que o ensino presencial ainda é fundamental e insubstituível como o tipo de ensino possível e de qualidade em nosso país para atender à demanda educacional dos estudantes mais pobres que estão na base da pirâmide social.

É fato que alguns estudantes tiveram êxitos e venceram essas barreiras citadas acima, ao conseguir dar continuidade à sua formação, e assim atingindo o aprendizado de novos saberes, visando alcançar a sua aprovação no exame que é o passaporte para a universidade pública, o ENEM. No entanto, é relevante também destacar que um percentual maior dos/das estudantes da rede pública não conseguiram superar as dificuldades da nova forma de aprendizado via ensino remoto.

Assim, diante dos problemas elencados, fazendo-se um balanço da realidade do ensino brasileiro hoje, frente a tais reformas e à situação da pandemia, pode-se dizer que a educação a ser ofertada não visa a formação integral dos educandos, pois a proposta desse Novo Ensino Médio acaba por especificar cada vez mais os saberes, fragmentando-os. Essa reformulação apesar de propor mais escolas em tempo integral, falar em protagonismo do aluno, não disfarça que a sua real ênfase é o ensino profissionalizante para inserção dos jovens no mercado de trabalho e, assim, se configurando como um retrocesso da educação brasileira.

A situação do ensino de Filosofia no contexto da referida Reforma se encontra em parte lançado à sua sorte, porque depende da escolha dos estudantes em relação a sua escolha dos itinerários formativos. Por isso, desde 2017, os \as professores \as da referida disciplina são convocados a fazerem uma reflexão sobre a sua prática e a sua formação docente, fazendo um movimento de reflexão crítica na tentativa de compreensão dessa reforma para, assim, intervir na possível acentuação do problema já existente que é o desinteresse por parte dolda discente no estudo da Filosofia. A sobrevivência da disciplina não pode ser relegada apenas a 
decisão do discente, porque cabe aos professores fazerem a sua resistência, com a finalidade de lutaram pelo espaço da Filosofia em sala de aula.

Apontamos minimamente a realidade do ensino de Filosofia até o contexto atual, na tentativa de compreender as dificuldades que o atravessam. O caminho a ser traçado a seguir diz respeito a análise do problema do desinteresse dos discentes em relação a Filosofia. Sobre isso, a investigação aponta que vários fatores contribuíram para o desinteresse dola discente diante da apresentação dos conteúdos filosóficos em sala de aula. Primeiro, é pertinente apontar os aspectos didático-pedagógicos e, dentre os quais, se pode mencionar o tempo irrisório de aula, a saber, 45 minutos semanais para desenvolver um tema e um problema filosóficos. Isso limita e dificulta a continuidade nas leituras dos textos de filosofia e de suas respectivas discussões, como também, o aprofundamento nos debates e a aplicação de outros recursos didáticos tais como: filmes, documentários, pesquisas em laboratório de informática, peças teatrais etc. Por não haver tempo suficiente para que este ensino seja respaldado na alteridade, ou seja, na vivência da autonomia participativa e efetiva dos\das estudantes e na aplicação de metodologias e recursos didáticos diversificados, continua vigorando o sistema educativo majoritariamente de ensino tradicional que se sustenta ainda na repetição e memorização dos manuais. O ensino de Filosofia, dessa forma, recai por vezes no que é menos importante, que é o andamento tão somente dos conteúdos dos livros didáticos - e isso de forma mecânica, sem a preocupação de que o/a estudante compreenda e desenvolva o seu olhar crítico sobre o conteúdo vivenciado e mediatizado por sua liberdade de pensar, de criar e de problematizar.

Além disso, o desinteresse pela disciplina está longe de ser um problema pontual, pelo contrário, essa é uma experiência comumente compartilhada entre os professores da área de Filosofia do Ensino Médio. Logo, é relevante olhar para a formação docente a partir de um viés crítico que esteja atrelado as dificuldades vivenciadas pelos las discentes em relação ao interesse permanente pelos conteúdos filosóficos. 


\section{Repensando a formação docente}

Pelos motivos até aqui expostos, constatou-se a necessidade urgente de reinventar a prática docente e, dessa forma, garantir a sobrevivência da disciplina de Filosofia. O ponto de partida nesse processo de refazer a formação docente inicia-se colocando esse ensino como objeto de investigação filosófica, na tentativa primeira de que não recorrer no erro de continuar levando a Filosofia para a sala de aula como um elemento estranho aos discentes. De fato, aqueles/as que não tiveram contato com a Filosofia no Ensino Fundamental, ao se depararem com ela no Ensino Médio, olham-na de forma enigmática e estrangeira ${ }^{3}$, pois muitas vezes, ela nunca foi vista, ouvida e pensada. Essa é a realidade compartilhada pelos $\backslash a s$ discentes do $1^{\mathrm{o}}$ ano quando são apresentados pela primeira vez aos temas, problemas e vocabulário da filosofia. No entanto, o desconhecimento prévio da filosofia não pode ser interpretado como a única razão para a sensação de que ela é algo enigmático e que não pode ser compreendida.

A hipótese levantada para a situação alarmante de desinteresse pela disciplina de Filosofia fundamenta-se na dicotomia entre teoria e prática vivenciada pelo professor da disciplina no decorrer de todo o processo de sua própria formação docente. Isso porque, nessa formação, aquilo que se propõe ser o ensino de Filosofia não se coaduna com o modo como é vivenciado esse ensino em sala de aula no Ensino Médio, nem com a construção do sentido da vida cotidiana dos futuros educandos. Por isso, é relevante esclarecer que a solução do problema vivenciado pelos docentes da área de Filosofia no Ensino Médio não diz respeito tão somente à sua prática docente.

$\mathrm{O}$ que se percebeu foi a pertinência em voltar-se para as respectivas formações acadêmicas, na tentativa de compreender o fenômeno investigado, a fim de apontar pistas, fundamentadas na pesquisa teórica e de campo com o intuito de promover mudanças significativas tanto no ato de

${ }^{3}$ Essa é a forma como alguns alunos enxergam a filosofia: como um estudo de assuntos que não lhe dizem respeito.

Filos. e Educ., Campinas, SP, v.13, n.1, p. 2020-2055, jan./abr. 2021 - ISSN 1984-9605 
ensinar quanto no de aprender o ensino de Filosofia no cenário do novo Ensino Médio.

Nesse recorte das formações acadêmicas, é pertinente dizer que a realidade de alguns cursos de licenciatura de Filosofia no Brasil revela-se, infelizmente, como sendo a de "[...] bacharelados enrustidos" (MATOS, 2015, p. 37), nos quais a discussão sobre a Filosofia na escola ou, do que seja de fato um ensino filosófico, perpassa a graduação de forma incipiente. O estágio supervisionado, ainda que seja uma etapa sine qua non $^{4}$ para os graduandos em licenciatura, não possibilita resolver o grande dilema de como transformar a Filosofia estudada na universidade em algo ao alcance de crianças e adolescentes. A fala é uníssona em se dizer que a Filosofia não se resume aos livros didáticos, menos ainda, a uma reprodução da história da filosofia, mas, a própria formação acadêmica trata de repetir o erro de uma grade curricular dissociada da realidade da vida dos/as discentes e da escola, como diz Matos (2015, p. 36):

[...] Em alguns momentos, somos levados a pensar que a própria instituição tornou-se o "fim" do seu trabalho, quando essa deveria ser "meio" e servidora da sociedade. Um sintoma desta visão é o descolamento existente entre o ensino superior e a escola básica. A escola pública parece ser considerada um "mal necessário", um lócus com o qual não interessa interagir.

A dificuldade de interação entre a escola e a universidade no contexto da formação do professor de Filosofia no Brasil pode ser decorrente da estruturação da grade curricular, em que majoritariamente se vê consolidada como uma história da filosofia predominantemente colonizadora, europeia, havendo uma quantidade mínima de disciplinas que versam sobre a História da Filosofia no Brasil. Em relação às disciplinas voltadas para o ensino de Filosofia, na maioria dos cursos de licenciatura, são ministradas pelos professores do curso de Pedagogia. Compreende-se que, se não há diversidade de filosofias, a própria universidade com essa escolha de

${ }^{4}$ Termo em latim que pode ser traduzido como "sem a/o qual não pode ser". 
componentes curriculares acaba por vitimar seus estudantes no sentido acadêmico e, portanto, profissional, pois, segundo Cabreira $(2015$, p. 7):

[...] toda vez que um estudante de filosofia cursa uma disciplina onde apenas constam autores europeus e norte-americanos, retirados da história oficial da filosofia de Tales a Habermas, [...] o estudante é submetido a um tipo de violência intelectual e institucional, baseada numa situação de unilateralidade e falta de simetria.

Além disso, constata-se outro problema nas formações, relativo ao desmerecimento de uma "filosofia desde o Brasil". Partindo-se dessa discussão, faz-se pertinente mencionar outra fala de Júlio Cabreira, na qual apresenta uma contribuição significativa no debate sobre o que ocorre frequentemente quando se discute a produção filosófica do Brasil.

A respeito de filosofia no Brasil, muitos dos que tomam parte em discussões estão totalmente convictos de que a produção filosófica europeia representa pura e simplesmente o pensamento universal, enquanto colombianos, brasileiros ou africanos, quando pensam os problemas que surgem de suas realidades, refletem a partir de suas procedências nacionais e não fazem autêntica filosofia universal. Pensam que quando alguém fala em "idealismo alemão" refere-se a algo destinado à humanidade, mas que quando alguém fala em "filosofia brasileira" não expressa nada que tenha sentido (CABREIRA, 2014, p. 2).

Essa postura de enaltecimento da filosofia europeia em detrimento da brasileira não foge da discussão sobre a formação do professor. Ao contrário, ela revela falhas de uma formação que incide diretamente no ensino do docente e tem como primeira consequência o distanciamento dos/das discentes em relação à Filosofia, pois a filosofia que é apreendida na

${ }^{8}$ Denominação apontada por Cabreira para referir-se a uma filosofia constituída desde o Brasil, mas que não se limita a uma definição de filosofia nacional. 
academia e levada ao âmbito escolar é, historicamente longínqua, tão descontextualizada que não dá ao/a discente em processo de formação docente a ideia de pertencimento, de que algo diz respeito ao sentido da sua realidade. Não é o caso de dizer ser irrelevante o estudo das principais áreas e história da filosofia, tampouco é o caso de reduzir a discussão à contabilização das disciplinas em áreas filosóficas versus as de prática pedagógica e currículo. Mas como afirma Tomazetti (2012, p. 92):

[...] é comum as disciplinas pedagógicas serem preteridas em favor das disciplinas propedêuticas, e, no tocantes aquelas, percebem-se muito docentes alheios a tais saberes, gerando a impressão de que conhecimentos pedagógicos podem ser adquiridos e utilizados em termos gerais, e não na especificidade do ensino da Filosofia.

O reflexo desse currículo revela-nos a necessidade de preocuparmonos com a formação docente. Afinal de contas, a formação do professor destina-se a um outro que frequentará a escola pública ou privada, uma escola que não tem sido suficientemente discutida, pensada e alcançada pelos cursos de Filosofia nas universidades. Estas têm diante de si o desafio de colocar a Filosofia feita neste país em diálogo com a realidade históricosocial em que se situa. Cabe-lhes valorizar as particularidades de uma terra e de um povo para que assim a Filosofia possa ser vivida e pensada com autenticidade e criatividade. Como problematiza Matos, que os futuros professores não sejam formados para serem “[...] prenunciadores de aulas, e, sim, serem pensadores abertos, sensíveis e comprometidos com sua prática e sua teoria" (MATOS, 2015, p. 36).

Como antes dito, buscaremos a seguir pistas filosóficas com o intuito de repensar a formação docente visando à reestruturação dessa prática na área de Filosofia no Ensino Médio, correlacionando-a com o contexto da vida dos/as discentes. Escolhemos como caminho metodológico e epistemológico a perspectiva filosófica e pedagógica de Edith Stein, para 
contribuir na elaboração de uma proposta pedagógica que contemple as lacunas e desafios da formação na área de Filosofia.

A filosofia de Stein elege o ser humano como tema principal de suas investigações. Suas reflexões sobre o conceito de formação estão atreladas à uma investigação prévia da constituição ontológica do ser humano, pois dá primazia a compreender o ser humano a partir das suas dimensões: corporal, psíquica e espiritual, vistas de uma forma integral. Para atingir o seu objetivo, escolheu o método fenomenológico como via de investigação dos fenômenos relacionados aos problemas humanos nas suas diversas perspectivas: social, pedagógica, antropológica, factual, filosófica, psicológica. Stein percebeu que, com o referido método, poderia descrever os fenômenos na sua essência de maneira objetiva, não se contentou com as reflexões das ciências naturais e humanas sobre quem era o ser humano. A referida filósofa considerou a fenomenologia como uma ciência rigorosa que possibilita atingir uma compreensão profunda da estrutura da pessoa humana por contrapor-se às visões positivista e neokantiana que vigoraram no seu contexto cultural e filosófico, pois a preocupação destas duas perspectivas filosóficas é tão somente investigar a origem, o alcance e o limite do conhecimento humano. Entretanto, como salienta Stein, a fenomenologia vai além daquelas visões filosóficas, pois tem como foco atingir a essência do que se mostra, o que significa dizer que, segundo Martins, Boemer e Ferraz (1990, p. 143), é uma “[...] trajetória que melhor expressa o caminhar em busca da essência do fenômeno".

Dessa forma, um projeto político de curso de uma licenciatura alicerçado na concepção de formação de Stein deverá buscar os meios assertivos de configuração da personalidade dos/das estudantes no decorrer do seu processo formativo. Para atingir esse intento, é importante que os/as professores/as formadores/as compreendam que:

Toda labor educativa que trate de formar hombres va acompañada de una determinada concepción del hombre, de cuáles son su posición en el mundo y su misión en la vida, y de qué 
posibilidades prácticas se ofrecen de tratar y formar al hombre. (STEIN, 2003, p. 582).

Essa compreensão fenomenológica de quem é o ser humano deve preceder toda investigação acerca dos problemas pedagógicos, pois, como adverte Stein (2003, p. 579):

[...] la idea del hombre es de relevancia decisiva tanto para la estructura de la pedagogía como para la labor educativa, será de urgente necesidad para estas últimas gozar de un firme apoyo en esa idea. La pedagogía que carezca de respuesta a la pregunta "¿qué es el hombre?" no hará sino construir castillos en el aire. Encontrar una respuesta a esta pregunta es la tarea de una doctrina sobre el hombre, de la antropología. Ahora bien, dista de ser evidente qué se debe entender bajo este término.

Toda prática pedagógica e a sua estruturação curricular, segundo Stein, deverão ser precedidas de uma investigação fenomenológica acerca da pergunta “quem é o ser humano?" enquanto um caminho para pensar o ato educativo como um ato de formação integral do ser humano. Então, para se pensar a formação no campo educacional, Stein afirma que não se deve limitar essa formação a uma mera transmissão de conhecimento de um indivíduo para o outro, ou seja, do educador para o educando, pois considera essa formação como um processo de colaboração mútua: o/a professor/a formador/a deverá possibilitar o desenvolvimento das potencialidades do/da educando/a, que se tornará aquilo que escolher ser, seguindo o itinerário de suas potencialidades internas. A formação não está relacionada com a exterioridade; não diz respeito tão somente à memorização de saberes, nomes, datas enciclopédicas; e, por fim, não se refere estritamente aos conhecimentos externos.

La formación no es la posesión de conocimientos exteriores, sino la configuración que la personalidad humana asume bajo la 
influencia de múltiples fuerzas formadoras, por ejemplo el proceso de esta formación. El material que hay que formar es la disposición corporal y anímica que el ser humano lleva consigo al mundo, así como los elementos que han de ser continuamente recibidos desde el exterior, e incorporados al organismo. El cuerpo los toma del mundo material, el alma de su entorno espiritual, del mundo de personas y de bienes que para su desarrollo están dados. (STEIN, 2013, p. 197).

O conceito de formação em Edith Stein não contempla os passos formativos enaltecidos pela pedagogia procedimental, que defende uma proposta pedagógica em que se valorizam somente os procedimentos mecânicos e a discussão acerca da estrutura ontológica do ser humano não é vista ou considerada como uma via relevante para fundamentar um projeto político de curso, pois como diz Mattéi (2002, p. 192), “[...] já não situa o saber nos conteúdos substanciais a ensinar ao aluno, mas nos métodos formais que se fecham em seus próprios procedimentos". Para Edith Stein, como se viu anteriormente, toda prática educativa que de fato esteja voltada para a formação autêntica do ser humano precisa estar atenta à compreensão da constituição ontológica do/a educando/a, a qual possibilita olhar para a sua capacidade de se autoformar no decorrer da construção de seu projeto de vida mediante sua liberdade e individualidade. Porém, para que isso aconteça, é preciso que o/a professor/a formador/a atente para a singularidade do educando/a, porque, como refere Alfieri (2014, p. 58):

$\mathrm{Na}$ pessoa humana, encontramos características (tipos de conteúdo) que são compartilhados por todos os seres de sua espécie (universal); porém, cada indivíduo reúne conteúdos de modo inteiramente singular, por sua maneira individual de realizálo.

Dessa forma, o conceito de formação de Stein instiga-nos e motivanos a refletir se a formação docente na área de Filosofia está de fato voltada 
para a construção significativa de como e de que modo se configura o caminho de uma formação humana dos/das futuros/as professores/as de Filosofia, na medida em que, o corpo docente esteja atento para o sentido de sua atuação teórica e prática. Essa atuação docente deverá estar alicerçada na compreensão e no reconhecimento da alteridade e na liberdade dos/das discentes como única via de oferecer-lhes uma formação autêntica ao contemplar filosófica e pedagogicamente as dimensões ontológicas: corpopsique-espírito. Essa concepção de formação docente alicerçada em Edith Stein, também é apresentada como uma proposta de redefinição do ensino de Filosofia que se vivencia no chão da escola para possibilitar uma mudança de olhar e de ação dos/das discentes perante os conteúdos filosóficos para assim, se sentirem motivados no contexto da Reforma do Ensino Médio a participarem de forma autônoma e criativa dos debates filosóficos e intervirem de forma significativa na realidade em que se encontram inseridos no seu contexto social e econômico.

\section{O ensino de Filosofia que vai à escola}

Continuando a investigação, pensemos agora sobre a Filosofia que está sendo levada à escola e sobre isso encontramos na fala de Gallo uma síntese das inquietações que versam sobre esse ensino, ou diga-se essa educação filosófica a ser construída com os(as) discentes. O referido autor diz:

Sabemos que a raiz latina do verbo 'educar' denota um ato de 'violência', em certo sentido: educar é conduzir alguém, promover a passagem - muitas vezes forçada - de um lugar a outro, de uma condição a outra. Podemos, então, falar numa educação filosófica? Será a filosofia um ato de condução forçada de uma condução a outra? Já não estará desgastada a afirmação da filosofia como transição de um certo 'senso comum' a uma certa 'consciência filosófica'? (GALLO, 2014, p. 205). 
Partindo dessa problematização, pensamos que fazemos sim, professor/a e alunos/as, uma travessia sem consulta de escolha, penosamente forçada sob a autoridade da criticidade, da razão, do conhecimento. Atravessamos com os/as discentes um caminho em direção ao saber, sob a ânsia de conduzi-los por um percurso na história da filosofia, se ocupando com os problemas recorrentemente postos em investigação. Mas, nós professores/as, muitas vezes, os deixamos ainda mais ignorantes de si mesmos/as, porque desqualificamos e desprezamos o que eles trazem para a sala de aula como saber e, assim, não o estimulamos ao processo de vivência da sua autonomia do pensar criativo e significador. Essa afirmação é corroborada pela fala de Tomazetti et al. (2012, p. 91):

A prática historiográfica encontra terra fértil em nossa cultura de valorização do argumento de autoridade, inibindo sobremaneira a criação filosófica com a formulação de problemas sobre o tempo presente. No âmbito do Ensino Médio, de alguma forma, essa tradição também se fez notar, mesmo que de forma superficial.

Dessa forma, na prática das aulas de Filosofia, é pertinente pensar: por que é relevante ensinar sobre a dúvida cartesiana, o dasein heideggeriano, ou ainda, a estética hegeliana para um aluno da periferia da Paraíba quando as urgências do seu cotidiano não dialogam com tais assuntos? Longe de ser um preconceito epistemológico, a provocação feita nos diz que a Filosofia ensinada na escola precisa dialogar com a realidade do/a estudante, com suas demandas. O currículo escolar carece de uma parcela construída conjuntamente com o/a discente, que considere o seu interesse, as suas reais inquietações, pois estas não são as mesmas dos filósofos do século VI. a.C. ou do século XVIII. Repeti-las para que simplesmente memorizem pensamentos alheios é um falso momento de reflexão. Bem sabemos que existe um conteúdo programático que se destina à demanda dos exames nacionais, mas, encerrar ou direcionar o objetivo do ensino para esse propósito é apequenar a Filosofia levada à escola. Essa Filosofia precisa ir além do currículo que se pauta na Reforma do Ensino Médio. É relevante 
ressignificar esse ensino mediante a construção de saberes comuns com os/as discentes. Por isso, como afirmam Tomazetti; Londero (2016, p. 5):

\begin{abstract}
Entendemos que ensinar é uma prática complexa, ainda mais nas condições de desigualdade social que o docente enfrenta face aos seus alunos e das diferentes condições de escolarização com que tem de lidar no sistema. Logo, podemos dizer que atualmente, torna-se necessário que os docentes sejam também discentes de seus saberes, que reflitam sobre sua prática e consigam trabalhar temas ou conteúdos em que possam fazer contextualizações históricas.
\end{abstract}

Para enfrentar essa realidade de desinteresse do/da discentes com o ensino de Filosofia, é realmente necessária não apenas a contextualização da Filosofia a ser levada para sala de aula; mas, sim um enraizamento dela na própria circunstância de vida dos docentes e discentes, de maneira que seja possível aqueles/as identificarem-se com ela na medida em que, como afirmou Stein, é relevante que o/a professora de Filosofia tenha uma compreensão do ser humano, ou seja, dos/das discentes na sua dimensão: corporal; psique e espiritual. Em outras palavras, para que a Filosofia deixe de ser uma disciplina desconhecida como aponta os/as discentes, ela deve ser representativa, de maneira que reconheçam traços daquilo que estuda, discute e problematiza como pertencentes à sua realidade. Isso não significa extinguir a História da Filosofia Ocidental, ou estudar apenas os filósofos latino-americanos, mas, levar uma proposta de escuta para a sala de aula em pé de igualdade com a proposta filosófica que abria espaço para o interesse dos/das discentes, na medida em que, seja garantido o espaço de discussão e exposição dos temas, problemas a serem pensados na construção do curso no ano letivo. Proporcionar essa abertura de escuta da fala dos/as discentes é tratá-los/as como iguais - iguais na possibilidade de escolherem de forma autônoma e significativa aquilo que será estudado em sala de aula, ao reconhecê-los/las pela sua capacidade de pensar, pelo direito de serem tratados não como um depósito de informação, mas, como sujeitos 
construtores de significados da realidade, ou seja, como participantes do processo de conhecimento a ser construído.

A abertura desse reconhecimento dos/das nossos/as discentes como iguais intelectualmente, sem tutela, nem distanciamento do que lhes interessa, implica na tentativa de fazer da Filosofia uma disciplina que tenha significado e possa ser desejada e se fazer presente na vida estudantil. Afinal, é valoroso lembrar o que nos diz Cerlleti (2009, p. 38): “[...] o essencial da filosofia é constitutivamente, inensinável, porque há algo do outro que é irredutível: seu olhar pessoal de apropriação do mundo, seu desejo, enfim, sua subjetividade." Portanto, é fundamental para se alcançar o êxito dessa disciplina e, consequentemente, a sua sobrevivência, tornar a filosofia um saber desejável para osłas discentes e, isso ocorrerá quando a entrelaçarmos com aquilo que se apresenta enquanto possibilidades de criação, de transformação da sua realidade mediatizadas pelo processo de compreensão do saber filosófico.

\section{O caminhar metodológico da pesquisa}

A metodologia escolhida para o desenvolvimento do problema da pesquisa foi a pesquisa-ação por ser um tipo de pesquisa de cunho intervencionista e participativa, pois como a define Thiollent (1986, p. 14):

[...] a pesquisa-ação é um tipo de pesquisa social com base empírica que é concebida e realizada em estreita associação com uma ação ou com a resolução de um problema coletivo e no qual os pesquisadores e os participantes representativos da situação ou do problema estão envolvidos de modo cooperativo ou participativo.

Dessa forma, a construção do problema da pesquisa, delineou-se pelo viés fenomenológico, procurando-se compreender o sentido do fenômeno a ser investigado: o desinteresse dos alunos pela disciplina de Filosofia no Ensino Médio. Um problema real, partilhado por muitos professores e que precisava ser investigado e resolvido, visando a sua 
sobrevivência nas instituições escolares frente a chegada do Novo Ensino Médio.

Assim, nos guiando pela metodologia construída por Thiollent, no que se refere a pesquisa-ação, a primeira fase da pesquisa foi a exploratória, que consistiu “[...] em descobrir o campo de pesquisa, os interessados e suas expectativas e estabelecer um primeiro levantamento (ou 'diagnóstico') da situação, dos problemas prioritários e de eventuais ações" (THIOLLENT, 1986, p. 48). O campo de pesquisa escolhido foi a Escola Estadual de Ensino Fundamental e Médio Francisco Ernesto do Rêgo, na cidade de Queimadas (PB). Nesse primeiro levantamento também foi definido o perfil dos sujeitos da pesquisa: os/as discentes do Ensino Médio, especificamente, das turmas do $1^{\circ} \mathrm{J}$ e $2^{\circ} \mathrm{A}, \mathrm{B}, \mathrm{D}, \mathrm{E}, \mathrm{F}, \mathrm{G}$.

Para fazer o levantamento dos dados e diagnosticar o problema da pesquisa, foram realizadas atividades pelas pesquisadoras juntamente com os sujeitos da pesquisa, tendo sido elaborado um questionário constituído por nove questões, dentre estas, questões de assinalar e dissertativas de natureza qualitativa buscando a compreensão do fenômeno.

O questionário foi respondido por 123 discentes e as pesquisadoras dividiram as respostas nos seguintes grupos: $1^{\circ}$ grupo: aqueles/as que disseram que gostam e querem cursar a disciplina; $2^{\circ}$ grupo: os/as que não gostam e não querem cursar; $3^{\circ}$ grupo: os/as que gostam da disciplina, mas, não querem cursar no ano seguinte com a implantação do Novo Ensino Médio. O percurso das etapas até aqui expostas condiz com o que Thiollent (1986, p. 58) definiu como sendo o seminário da pesquisa:

O seminário central reúne os principais membros da equipe de pesquisadores e membros significativos dos grupos implicados no problema sob observação. O papel do seminário consiste em examinar, discutir e tomar decisões acerca do processo de investigação. [...] O seminário centraliza todas as informações coletadas e discute as interpretações. 
Após a fase das divisões dos grupos e coordenação das atividades, as pesquisadoras prosseguiram com a etapa de centralização das informações levantadas a partir do questionário aplicado, seguindo os passos do método fenomenológico que foram sendo vivenciados nos seus três movimentos: o primeiro, o de descrição do fenômeno; o segundo, em que se fez uma redução fenomenológica, buscando-se atingir a essência do fenômeno investigado e; por último, apresentou-se a compreensão fenomenológica da essência do fenômeno. É relevante esclarecer esses três movimentos da investigação fenomenológica segundo Morais; Galiazzi (2016, p. 30):

[...] O primeiro consiste num olhar atento para o fenômeno, procurando percebê-lo em sua totalidade. Nesse momento procurase vislumbrar alguma luz que o ser lança, a partir de sua presença, sobre o que ainda se apresenta velado. $\mathrm{O}$ segundo momento resume-se a descrever o fenômeno sob investigação, sem, entretanto, deixar-se levar pelas crenças e preconceitos. E descrevê-lo à luz da redução fenomenológica. Por fim, o último momento consiste em um mergulho nos aspectos essenciais do fenômeno.

Depois de colhidas as falas dos/das discentes e analisadas a partir do método fenomenológico, o resultado será discutido e interpretado. Segue abaixo a apresentação da compreensão dos dados coletados.

6. Discussões e Resultados dos dados

Figura 1 - Gráfico geral dos alunos do Ensino Médio que responderam o questionário.

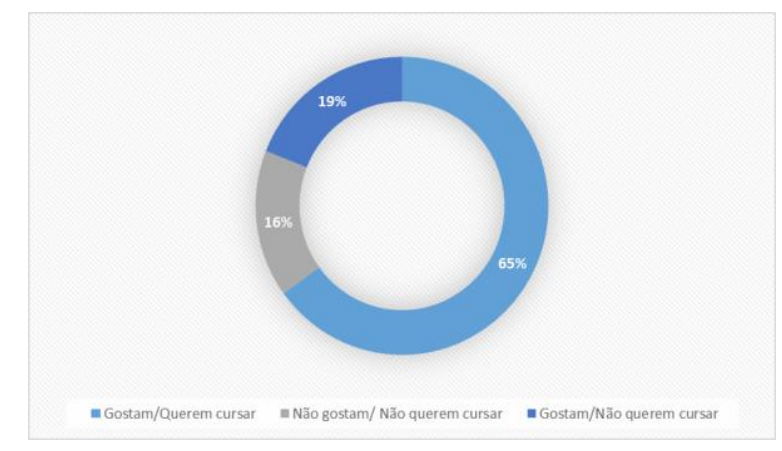


Fonte: dados da pesquisa

A aplicação do questionário teve como objetivo fazer um levantamento de dados mais preciso do fenômeno do desinteresse pela disciplina de Filosofia, podendo-se, assim, abordá-lo de modo qualitativo e quantitativo. Além disso, buscou-se abrir espaço para a expressão dos reais problemas que os/as discentes enfrentavam ao estudar os conteúdos filosóficos. Assim, por meio de seu lugar de fala, eles/elas pudessem dizer não apenas sobre o seu desinteresse e as suas dificuldades, como também, apontar o que precisaria melhorar nas aulas e na metodologia utilizada pela professora para facilitar a apreensão dos sentidos e contextos dos temas, problemas, história da filosofia com à sua realidade e, dessa forma, possiblitar a sua aprendizagem. O primeiro gráfico mostrou o cenário de aceitação e rejeição da disciplina de Filosofia nas turmas que participaram da pesquisa. O número total de discentes que gostam e querem cursar a disciplina, se percebeu maior do que o grupo daqueles/as que não gostam.

No entanto, em um cenário de instabilidade da disciplina de Filosofia na Reforma do Ensino Médio, se desvelou nos dados coletados um percentual signifcativo de $35 \%$ de discentes que disseram não gostar da disciplina, somando-se ao grupo de discentes que disseram que gostam da disciplina, mas, não querem estudá-la no ano seguinte. Esse primeiro gráfico representa o número de sujeitos reais que estão na escola e que não se interessam pelo prosseguimento dos estudos em Filosofia no Ensino Médio. O problema levantado no artigo está direcionado a essa porcentagem de discentes que não empatizam com os temas filosóficos, problemas, metodologia e didática utilizados pela professora. $\mathrm{O}$ sentido apreendido das falas dosldas discentes possibilitaram as pesquisadoras elencar algumas respostas comuns que versaram sobre as dificuldades vivenciados por eles/elas.

Dentre as diculdades mais recorrentes em suas falas, se pode destacar como as mais relevantes para o tema proposto nesse artigo as seguintes: o pouco tempo da hora/aula semanal, problema anteriormente 
denunciado, somando-se à precarização da estrurura fisíca da escola onde se realizou a pesquisa. A precarização foi considerado na pesquisa como um aspecto de interferência na qualidade do ensino, pois está expressamente registrada na fala dos/das discentes, a exemplo do que diz o discente A, quando afirma: "a principal dificuldade é o barulho da sala ao lado, que dificulta ouvir a professora, e o tempo de aula é muito curto". A mesma denúncia se faz presente na fala do discente B: "geralmente, não tenho dificuldades para aprender filosofia, mas minha escola não oferece uma estrutura adequada para melhorar meu ensino". Essa não é uma realidade isolada, porque muitas escolas públicas brasileiras possuem infraestruturas sem as condições adequadas para seu funcionamento, por exemplo, a escola pesquisada funcionava em um clube de festas da cidade e, as salas separadas por madeirites e, assim, prejudicando como se desvala na fala dos discentes o ensino e a aprendizagem de qualidade.

Dando prosseguimento à exposição dos gráficos por séries, a seguir temos um gráfico da turma do $1^{\circ}$ ano e outro das turmas de $2^{\circ}$ anos.

Figura 2 - Gráfico da turma do $1^{\circ}$ ano do Ensino Médio que

respondeu o questionário.

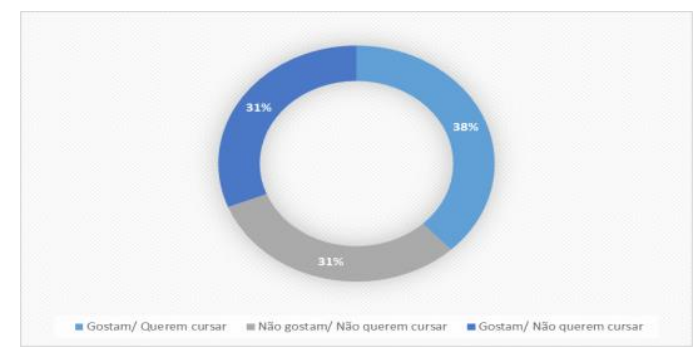

Fonte: dados da pesquisa

Diferentemente do exposto no primeiro gráfico geral, a quantidade dos/das discentes do $1^{\circ}$ ano que não desejam estudar filosofia, somado ao segundo grupo daqueles/as que gostam, mas não desejam cursá-la no ano seguinte, é maior do que o percentual daqueles/as discentes que querem cursar a disciplina na próxima série. É no $1^{\circ}$ ano que temos uma situação mais crítica de negação e desinteresse pela disciplina, e os números refletem essa situação em sala de aula, grande parte dos/das discentes não se concentram na aula e, por isso, também não interagem com os temas e 
problemas apresentados e discutidos pela professora. Não se pode dizer que todos/as os/as discentes no $1^{\circ}$ ano têm essa postura de desinteresse, no entanto, esse é a série de menor envolvimento com a disciplina.

Podemos analisar que isso se dá primeiramente, mas não unicamente, por ser este o primeiro ano de contato com a disciplina para muitos. É possível identificar essas questões na fala dos/das próprios/as discentes ao responderem à seguinte pergunta: Quais são as suas dificuldades para aprender os temas filosóficos?, dessa forma, o discente C diz: "acho que é muito complexo para aprender, assim de começo, mas com o passar das aulas dá pra aprender um pouco". Também podemos apontar a questão da falta de concentração como outra dificuldade desvelada na fala da discente $\mathrm{D}$, ao responder a mesma questão colocada mais acima: "Todos, porque eu não consigo ficar focada nas coisas muito tempo, com qualquer coisa me distraio fácil, mas às vezes tenho menos dificuldades"; ou ainda, na fala do discente E: "minha dificuldade é que eu não presto atenção nas aulas". Esse é um problema entrelaçado, por vezes, com a falta de maturidade do estudante, algo a ser construída durante a sua própria trajetória de vida acadêmica e pessoal durante os três anos do Ensino Médio. Esse choque de transição, a sua saída do Ensino Fundamental para o Ensino Médio se revela nesse primeiro ano, algo que se soma, ao desconhecimento e o primeiro contato com os conteúdos da disciplina de Filosofia. Certamente, para nós professoreslas, esse ensino na $1^{\text {a }}$ série no Ensino Médio é desafiador, pois ele sedimentará a possibilidade ou não da continuidade desse estudo nos anos seguintes.

Tornar-se relevante esclarecer que a compreensão das pesquisadoras diante dessas dificuldades que se mostraram com a fala dos/das discentes, não é considerar como inteiramente reprovável ou não inensinável os contéudos filosóficos e, também, o desmerecimento da formação docente nas universidades públicas do país, pois, apesar das falhas denunciadas nas falas dos/das discentes, esse ensino não deixa de buscar provocar naqueles/las a sua criticidade e, assim, retirá-los/las da apatia tanto dos conhecimentos filosóficos. Esse movimento de saída do/da discente da 
passividade em direção ao questionamento, à reflexão, está exposto na resposta da discente $\mathrm{F}$, quando responde a pergunta: As aulas de filosofia são interessantes? e diz o seguinte: "são interessantes porque 'ela' faz perguntas que normalmente não nos perguntaríamos no dia a dia". Também aponta na mesma direção o discente $G$ em sua fala: "sim, são interessantes, pois a professora traz coisa que desperta a curiosidade, minha, como aluno". Essas falas desvelam para as pesquisadoras a compreensão de que o ensino de filosofia apesar das dificuldades apontadas, ainda consegue alcançar êxito, na medida em que, subjetivamente desperta minimamente no/na discente o seu desejo, a sua curiosidade pelo pensar crítico. Por isso, como diz Edith Stein é relevante que a educaora/or compreenda o ser humano nas suas dimensões: corporal, psicológica e espiritual para assim buscar a partir do respeito da subjetividade dos/das discentes, o seu engajamento na estruturação das possíveis intervenções na solução do problema do seu desinteresse pelos conteúdos filosóficos.

Figura 3 - Gráfico das turmas do $2^{\circ}$ ano do Ensino Médio que responderam o questionário.

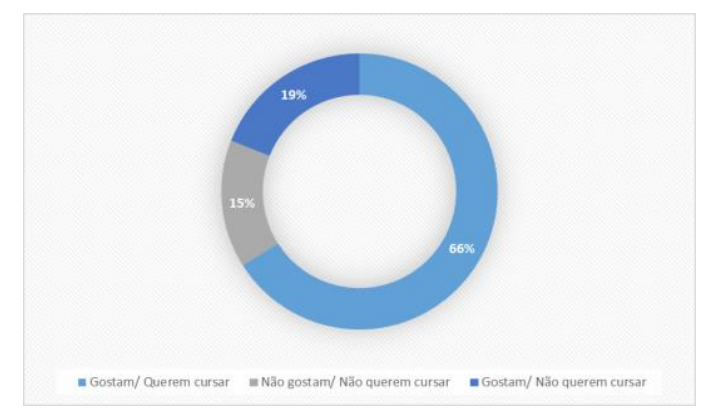

Fonte: dados da pesquisa

As turmas do $2^{\circ}$ ano se apresentaram com o maior quantitativo de participantes da pesquisa. Os resultados destas turmas assemelham-se com os do gráfico geral, diferentemente do gráfico do $1^{\circ}$ ano, que é um quadro mais negativo em relação ao percentual de discentes que pretedem continuar estudando nas futuras séries a disciplina de Filosofia. Apesar da diferença quantitativade entre os gráficos, o que eles refletem em comum, certamente, é a percepção da possível perda significativa de discentes que 
desejam dar continuidade aos estudos filosóficos. $\mathrm{Na}$ análise das falas dos sujeitos da pesquisa, revelam as dificuldades vivenciadas por estes nas aulas de Filosofia ao apresentarem os seguintes argumentos que dizem respeito: à complexidade dos temas, considerados difíceis de entender; a necessidade de que sejam melhor explicados, relacionados e contextualizados com a sua realidade.

Quando os sujeitos da pesquisa respondem a questão: “ $A$ metodologia utilizada pela professora é acessível à aprendizagem?", é possível identificar nessas respostas as lacunas da formação docente. Essas lacunas refletem a falta de conexão dos currículos nas licenciaturas, que são preestabelecidos, com a realidade dos discentes, como também, falta a essa formação uma investigação acerca da compreensão de uma concepção de ser humano que fundamente toda prática educativa e, estas se desvelam nas falas seguintes, para o discente $\mathrm{H}$ : "a professora ensina bem, só que é a matéria mesmo que é meio complicada, confusa e estranha"; ou ainda, como consta na fala do aluno I, quando afirma que é preciso: "mais análise sobre nossa época atual, não apenas se basear no pensamento de antigos filósofos".

Vê-se, assim, que as dificuldades anunciadas pelos/as discentes denunciam as suas necessidades reais no processo ensino-aprendizagem enquanto sujeitos constituidores dos significados da realidade em que estão inseridos. Não há como burlar as falhas que se apresentam no ensino, é preciso se implicar, pois toda mudança querer a responsabilidade dos/das docentes em assumir ações que promovam mudanças significativas no âmbito em que as mesmas se apresentam, ou seja, no âmbito escolar. Se reitera que as falhas dizem respeito à valorização de um currículo acadêmico no qual as teorias ensinadas estão dissociadas do contexto do trabalho escolar do futuro docente em Filosofia, tornando-o prenho de falhas para desempenhar a docência no contexto educacional do Ensino Médio. Para contribuir com o posicionamento das pesquisadoras em relação à formação ofertada pelas universidades públicas brasileiras, é relevante apontar o que diz mais uma vez Matos (2013, p. 45): 
[...] Os livros, as grandes teorias, as escolas de pensamento cumprem uma função específica dentro da sua formação, mas não são tudo, nem definem, a priori, o modo de atuar como docente. É necessário atentar para a realidade, que é muito mais rica e complexa, e rever, à luz de suas provocações, todo esse volume de saber sistematizado, o qual, por sua vez, origina novos estímulos em face dessa realidade sempre dinâmica.

Assim, ratificando a fala de Matos, é pertinente problematizar a formação docente que se inicia com a apreensão da teoria filosófica; porém, no seu decorrer, estabelecer uma ponte com as necessidades da escola, pois a teoria sozinha não é suficente para mudar essa realidade de negação, de desinteresse dos/das discentes do Ensino Médio perante a Filosofia. É relevante, no processo de formação, o/a futuro/a professor/a apreender teorias que possibilitem, mediante contextualização, efetivar uma quebra da repetição dos manuais, a exemplo da solicitação feita pelo discente I. Fazer isso é unir teoria e prática. Não é preciso negar a história da filosofia, e os seus respectivos representantes, mas trazê-los à sala de aula de forma que dialoguem com os/as dsicentes para que ganhe sentido o que está sendo estudado, orquestrando-se práticas de intervenção e atividades conjuntas com os/as mesmos. Vale inseri-los efetivamente no ensino - afinal, este é algo que lhes está sendo ofertado, como diz Matos (2013, p. 46):

A relação teoria/prática deve, então, ser encarada como um princípio do qual não dá para abrir mão. É problematizar a prática, alterar a teoria; buscar na prática parâmetros para 'testar' a teoria, e na teoria o suporte para a leitura da prática; modificar a prática em função dos achados de sua teorização; enfim, colocar-se num processo de escuta e aprendizado permanentes. Não é só! Teoria e 
prática são elementos catalisadores do trabalho pedagógico desenvolvido na escola, na sala de aula, no currículo em ação.

Conjuntamente, as pesquisadoras e os participantes da pesquisa efetivaram o segundo passo para modificar essa realidade de desinteresse pela Filosofia ao discutirem as respostas mais frequentes do questionário, buscando realizar uma interpretação desses dados. Esse segundo passo, consistiu na discussão com os/as discentes sobre as suas dificuldades e sugestões - momento do tête-à-tête em que reforçaram aquilo que já haviam respondido no questionário que foi o primeiro passo da pesquisa. Juntos pesquisadoras e discentes pensaram sobre as inovações metodológicas e didáticas que possibilitassem uma melhor e qualitativa vivência das aulas. Assim, discutiram e chegaram num consenso sobre as atividades didáticas e metodológicas que poderiam falicitar e incentivar o interesse pelos temas e problemas filosóficos, as sugestões dadas foram as seguintes: indicação de filmes e textos para serem assistidos e lidos, levando em consideração o contexto da realidade dos/as discentes para tornar significativos os conhecimentos filosóficos apresentados em sala de aula. Nesse momento da construção da intervenção se percebeu que houve uma resistência inicial dos discentes em protagonizar esse momento em que eles foram convidados a participar e escolher juntamente com as professoras as metodologias para se construir os passos da aula. Essa resistência evidencia o reflexo do engessamento acarretado pela recorrência das aulas expositivas, como se o ensino de Filosofia se sustentasse apenas pela via da explicação do professor ao/a discente, ao mantê-lo/la na condição de mero espectador e não como protagonista da sua aprendizagem significatica e transformadora.

O terceiro momento da pesquisa buscou continuar a investigação do que fazer para despertar o interesse daqueles/as que disseram não querer estudar Filosofia. As pesquisadoras compreenderam que precisavam insistir na pergunta: "O que lhe interessa?", para que os/as discentes 
pudessem pensar sobre essa pergunta provocativa, sendo esse o norte da discussão. A turma foi dividida em grupos, e cada grupo elegeu um/uma representante para as apresentar as respostas dos integrantes do grupo. A pergunta foi lançada aos discentes de forma mais ampla atingindo intencionalmente não só os conteúdos filosóficos como também as suas possibilidades de se constituirem enquanto sujeitos livres se, portanto, como aqueles que estimulados pela curiosidade buscam novos sentidos para a sua realidade. A pretensão não era fazer uma tentativa forçada para assuntos da Filosofia, mas, sim, apontamentos de quais são de fato as suas curiosidades e intenções acerca da sua vida enquanto um ser social e ético.

As respostas apresentadas pelo/a representante de um grupo em particularmente chamou a atenção das pesquisadoras, pois as suas colocações são ricas em sugestões sobre temas a serem debatidos filosoficamente nas aulas de Filosofia. É relevante mencionar a fala da discente M que escreveu:

[...] a fé e a razão desperta seu interesse, além de que é um tema que causa polêmica e é muito debatido. Também sugeriu algo pelo qual possui interesse: visitar conventos, igreja e centros espíritas. Além disso, poderíamos debater sobre a importância da religião em nossas vidas.

A sugestão do discente do mesmo grupo denominado de $\mathrm{T}$ foi a seguinte:

[...] filosofar no geral desperta seu interesse, visto que é ter uma reflexão madura na troca de ideia em nosso cotidiano. E, também, a busca em desenvolver cada vez mais um pensamento. Além disso, filosofar nos permite ampliar e aprofundar o nosso olhar, os nossos valores e os princípios que nos guiam em nossa jornada pessoal de autoconhecimento e autorrealização. 
Por fim, e não menos interessante, temos a resposta da discente $\mathrm{K}$, que diz:
As teorias da evolução, diferentes religiões, debater sobre a humanidade e seu atual estado, seria algo que iria interessar bastante a K. e despertaria seu interesse. Além disso, a leitura e dicas de como se expressar melhor despertariam sua curiosidade.

As respostas dadas revelou as múltiplas possibilidades de como levar a Filosofia à escola ao buscar a participação efetiva dos/das discentes para nortear a posssilibidade de êxito nas escolhas do que será estudado e debatido em sala de aula e, também, na construção de um ensino de Filosofia significativo para a vida acadêmica e pessoal dos/das discentes.

Partindo dessa compreensão se mostrou relevante a escuta das falas dos/as discentes e, assim, envovê-los numa consulta de caráter intervencionista de viés fenomenológico para envolvê-los/las na solução do problema da falta de interesse pela disciplina de Filosofia. Assim, redirecionamos nosso ponto de partida quanto aos temas a serem estudados para as urgências apontadas, a partir da realidade daquele/a, investigar as suas inquietações, as suas curiosidades, fomentando sua posição de sujeito desejante de saber. Portanto, partir dessas falas, se tornou possível nortear a intervenção, na busca de alcançar uma melhoria na intensidade do desejo dos/das discentes em se aproximar pela vivência da reflexão filosófica da sua realidade de vida para assim compreendê-la e criar novos sentidos de modo intersubjetivo.

\section{Considerações Finais}

Diante da investigação realizada ao se refazer o percurso do ensino de Filosofia no Brasil nos anos mais recentes, e tomando como ponto de partida as modificações que nos apresenta a Lei 13.415/2017, insistimos em dizer que é primordial sedimentar o espaço da Filosofia nos currículos oficiais. Essa luta necessária da Filosofia nos referidos documentos também 
ocupa um outro lugar de atuação, que é a sala de aula. Foi a partir desse lócus que buscamos a compreensão da essência do fenômeno investigado, a saber, o desinteresse pela disciplina de Filosofia, desvelado por meio da fala dos sujeitos da pesquisa. Desse modo, foi possível perceber o fosso entre o saber apreendido durante o processo formativo do/a professor/a do Ensino Médio nas instituições de ensino e a realidade da escola e dos/as discentes em sua vida cotidiana e, a necessidade de realizar intencionalmente uma intervenção signficativa, logo, constituida pelas pesquisadoras e sujeitos da pesquisa para assim, encontrar as possibilidades de compreensão e reestruturação práticas pedagógicas e didáticas para o ensino de Filosofia.

Reiteramos que a tarefa de repensar a formação docente e o ensino de Filosofia requer um trabalho intersubjetivo que busque investigar e problematizar o que está posto nos documentos oficiais, somando-se ao trabalho a ser desenvolvido pelo/a futuro/a professor/a da área de Filosofia. Esse foi o movimento constitutivo do presente trabalho, pois as respostas precisas para a sobrevivência do ensino da Filosofia se baseiam tanto na perspectiva doa/as discentes quem a Filosofia se endereça quanto pelo/a professor/a, que ocupa a função de ser mediador/a desse ensino. A escuta e reformulação ampararam-se na posição dos dois sujeitos do processo de ensino-aprendizagem: docente/discente e, baseando-se também na importância do pensameno steiniano ao afirmar que toda problematização da formação docente requer, por parte do/a professor/a formador/a e do/a futuro/a professor/a, uma compreensão das dimensões do ser humano corpo-mente-espírito -, atentando para a singularidade e a liberdade dos/as discentes no seu processo formativo. Processo esse que se inicia na universidade, na formação inicial do docente, mas, que deve se estender à futura formação do/a discente no ensino médio.

Quanto a sobrevivência desse ensino, acreditamos que não haverá caminho possível para a sua continuidade se não houver do/a próprio/a discente a sua disposição, o seu desejo de conhecer, vivenciar e resignificar os temas e problemas da Filosofia. A pretensão desse trabalho, enquanto 
professoras e pesquisadoras recai na tentativa de fazer da Filosofia algo interessante a quem se destinaa apreendê-la no chão da escola. Para isso é preciso realizar na prática docente o diálogo profícuo da Filosofia com a vida dos/das discentes - para que esta, se torne desejada e significante.

\section{Referências}

CABRERA, Julio. Europeu não significa universal. Brasileiro não significa nacional. Revista Brasileira de Humanidades. Ano 1, No 2. Nov/Dez 2014, Jan. 2015. Disponível em: http:// filosofojuliocabrera.blogspot.com/2015/03/europeu-nao-significauniversal.html. Acesso em: 24 de Março de 2019.

CABRERA, Julio. O estudante de filosofia como "vítima acadêmica". (Uma reflexão sobre razão vitimária desde Enrique Dussel e Paulo Carbonari). Disponível em: https://www.enriquedussel.com/txt/Textos Articulossobre-ED/O estudante filosofia vitima-J.Cabrera.pdf. Acesso em: 29 de Março de 2021.

CERLETTI, Alejandro. O ensino de filosofia como problema filosófico. Tradução: Ingrid Müller Xavier. Belo Horizonte: Autêntica Editora, 2009.

COSTA, Regis Clemente da; SUBTIL, Maria José Dozza. A ditadura militar no Brasil e a proibição do ensino de filosofia: entre o tecnicismo e a subversão política. Imagens da Educação. Maringá - PR. v. 6, n. 2 (2016). Disponível em:http://periodicos.uem.br/ojs/index.php/ImagensEduc/article/view/2 8805. Acesso em 03 de Julho de 2019.

GALLO, Sílvio. O macaco de Kafka e os sentidos de uma educação filosófica. In: Walter O. Kohan (org). Politicas do Ensino de Filosofia. Rio de Janeiro: DpA - 2014. Disponível em: https://silo.tips/download/o-macacode-kafka-e-os-sentidos-de-uma-educaao-filosofica-1. Acesso em: 29 de março de 2021.

HUSSERL, Edmund. Ideias para uma fenomenologia pura e para uma filosofia fenomenológica. Aparecida: Ideias \& Letras, 2006.

Filos. e Educ., Campinas, SP, v.13, n.1, p. 2020-2055, jan./abr. 2021 - ISSN 1984-9605 
LINDBERG, Christian. O ensino de Filosofia e a reforma educacional: o que fazer?. Disponível em: http://anpof.org/portal/index.php/en/comunidade/coluna-anpof/2052o-ensino-de-filosofia-e-a-reforma-educacional-o-que-fazer. Acesso em: 05 de Julho de 2019.

MARTINS, Joel; BOEMER, Magali Roseira; FERRAZ, Clarice Aparecida. A fenomenologia como alternativa metodológica para pesquisa: algumas considerações. Rev. Esc. Enf. USP, São Paulo, 24(1):139-147, abr. 1990. Disponível em: https://doi.org/10.1590/0080- 234199002400100139. Acesso: 10 de nov. 2020.

MATTÉI, Jean- François. A barbárie interior: ensaio sobre o i-mundo moderno. Tradução Isabel Maria Loureiro. São Paulo: Editora UNESP, 2002

MATOS, Junot Cornélio. Formação de professores de filosofia: proposições para o debate. EccoS Revista Cientifica, Universidade Nove de Julho, São Paulo, núm. 38, pp. 3141 septiembre-diciembre, 2015. Disponível em: http:/ / www.redalyc.org/articulo.oa?id $=71545304003$. Acesso em: 18 de Julho de 2019.

MATOS, Junot Cornélio. A formação pedagógica dos professores de filosofia: um debate, muitas vozes. Edições Loyola, São Paulo - Brasil, 2013.

MORAIS, Roque; GALIAZZI. Análise textual discursiva. 3. ed. rev. e ampl. Ijuí: Editora Unijuí, 2016.

PIOLI, E.; SALA, M. Reforma do Ensino Médio e a formação técnica e profissional. Revista USP, (127), 2020, p. 69-86. (Dossiê Ensino Público). Disponível em: https://www.revistas.usp.br/revusp/article/view/180047 . Acesso em: dia 03 de Janeiro de 2021.

STEIN, Edith. Estrutura de la persona bumana. In: Obras completas: Escritos Antropológicos y pedagógicos. V. 4. Madri/Burgos:Vitória Ediciones El Carmen/Editorial de Espiritualidad e Editorial Monte Carmelo, 2003. 
THIOLLENT, Michel. Metodologia da Pesquisa-ação. São Paulo: Cortez: Autores Associados, 1986. (Coleção temas básicos de pesquisa-ação).

TOMAZETTI, Elisete Medianeira et al. Pesquisa sobre ensino da filosofia e formação docente: percursos e incursões. In: DIEZ, Carmen Lúcia Fornari (org). Instigar a pensar e a questionar: o sentido do ensino de filosofia. Campinas - São Paulo: Mercado das Letras, 2012. --(Série educação geral, educação superior e formação continuada do educador).

TOMAZETTI, Elisete Medianeira; LONDERO, Márcia Eliana Araújo. Ensino de filosofia: necessidades formativas. Disponível em: http://coral.ufsm.br/gpforma/2senafe/PDF/008e1.pdf. Acesso em: $17 \mathrm{de}$ Julho de 2019.

Submetido em: 30/01/2021

Aceito em: 27/04/2021

Publicado em: 12/05/2021 